\title{
Cerebellar Vein
}

National Cancer Institute

\section{Source}

National Cancer Institute. Cerebellar Vein. NCI Thesaurus. Code C53032.

A superficial vein that is located on the cerebellum and that drains the cerebellum. 